\title{
Modelling of upwelling in the coastal area of Cabo Frio (Rio de Janeiro - Brazil)
}

\author{
Carlos Carbonel \\ Laboratorio Nacional de Computação Científica ( $\mathrm{LNCC} / \mathrm{CNPq}$ ) \\ (Lauro Müller 455, Botafogo - 22290-160, Rio de Janeiro, RJ, Brazil)
}

\begin{abstract}
A $11 / 2$ reduced-gravity model is proposed to study the hydrodynamic and thermodynamic features of the coastal upwelling area of Cabo Frio (Rio de Janeiro-Brazil). The vertical structure of the model is described by an active layer overlaying a deep inert layer where the pressure gradient is set to zero. For the upper layer, the model includes the turbulent version of the momentum, continuity and heat equations. The conservation of heat is represented by a transport equation to describe the thermodynamic changes of the sea surface temperature (SST). The solution domain includes open boundaries in which weakly-reflective conditions are prescribed. Solutions are found numerically on a uniform grid and the fundamental equations are approximated by the finite difference method. Numerical experiments are performed to evaluate the dynamic response of the coastal area of Cabo Frio forced by uniform and non-uniform wind fields. The solutions differ considerably depending on the orientation of the winds. East and northeast winds correlate with colder waters in the zonal coastline of this area and the presence of flows toward Cabo Frio correlates with north wind components. The proposed model is validated with the numerical simulation of an observed event of upwelling, where a timedependent and non-uniform wind field develops a SST pattern similar as the observations, particularly the extension of the cool water plume in south-west direction and the rapid time variation of the SST.
\end{abstract}

Resumo: Um modelo de gravidade reduzida de $11 / 2$ camada é proposto para estudar as características hidrodinâmicas e termodinâmicas da área costeira de Cabo Frio (Rio de Janeiro Brasil). A estrutura vertical do modelo é descrita por uma camada ativa sobre uma camada profunda sem movimento onde o gradiente de pressão é zero. Para a camada superior, o modelo incluí a versão turbulenta das equações de momentum, continuidade e calor. A conservação do calor é representada por uma equação de transporte para descrever os câmbios da temperatura superficial do mar (TSM). O domínio de solução inclui fronteiras abertas onde condições debilmente refletantes são impostas. As soluções são obtidas numericamente numa malha uniforme e as equações são aproximadas usando o método de diferenças finitas. Experimentos numéricos são efetuados para evaluar a resposta dinâmica da área costeira de Cabo Frio gerada por distribuições de ventos uniformes e não uniformes. As soluções diferem bastante dependendo da orientação dos ventos. Ventos $\mathrm{E}$ e ventos NE correlacionam com águas frias na linha costcira zonal desta área, e a presença de correntes na direção de Cabo Frio correlacionam com componentes de vento $\mathrm{N}$. O modelo proposto é validado com uma simulação numérica de um evento de ressurgência, onde uma distribuição de vento não uniforme e dependente do tempo gera uma distribuição de TSM similar às observações, particularmente a extensão das águas frias na direção SO e as variações da TSM no tempo.

Descriptors: Coastal upwelling, Numerical modelling, Cabo Frio .

Descritores: Ressurgência Costeira, Modelagem numérica, Cabo Frio. 


\section{Introduction}

Coastal upwelling is an important process because it brings nutrient rich water to the surface, thereby allowing the development of phytoplankton blooms. Furthermore, the coastal currents and vertical mixing within the diurnal thermocline provide a way of dispersing pollutants that are located close to ports or industrialized cities. Coastal circulations are often characterized by a meanderlike surface flows (Guillen \& Calienes, 1981), associated with the presence of cold surface temperatures in form of plumes and intrusion of warm oceanic waters. Coastline geometry, bottom topography as well as the driving wind fields, are all likely important for determining the transient response of coastal areas (Hurlburt, 1974; McCreary $\&$ Kundu, 1988). Major areas of coastal upwelling are located off the Peruvian coast, Oregon coast (USA) and northwest Africa. However, coastal upwelling also occurs at many other places in the world oceans, including the coastal area of Cabo Frio in Rio de Janeiro (Allard 1955; Mascarenhas et. al., 1971; Ikeda et. al., 1974).

There are numerous papers about circulation in coastal areas, some of them using analytical methods (Crepon \& Richez, 1982, McCreary et. al., 1989). Numerical models have difficulties simulating coastal upwelling events, for the reason that some processes and features such as the upwelling, downwelling, coastal jets and mixing are very poorly resolved by their grids, because the coastal region of interest is generally part of a much larger computational domain. Additionally, the delimitation of the computational domain implies that it is necessars to define suitable houndars conditiom

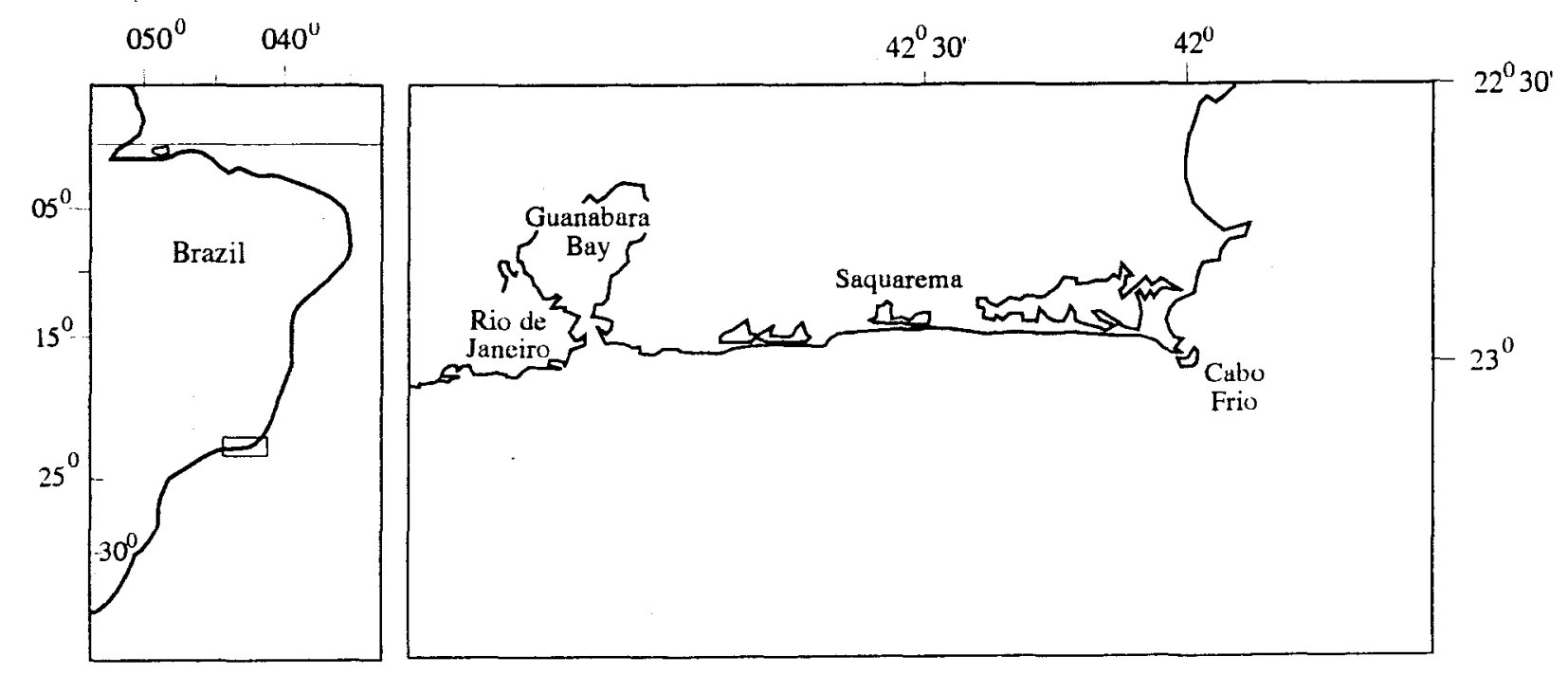

Fig. 1. Coastal area ol (atho troce. at open boundaries. Many types of open boundary conditions have been reported, all with the purpose of trying to eliminate the artificial reflection of waves at the open boundaries (Chapman, 1985). The open boundary conditions, based on the characteristic form of the governing equations for shallow water waves (Verboom, 1982), could be very effective for situations encountered in estuaries (Verboom et. al., 1983 ) and for wind-driven ocean problems (Carbonel, 1982, 1992).

The purpose of this work, is to investigate using a $1 \frac{1}{2}$ layer model, the wind driven upwelling dynamic of the coastal region of Cabo Frio, particularly the generation and evolution of upwelling plumes, which is an observed feature in this region. This paper describes idealized numerical calculations that simulate the coastal ocean's response to uniform east, uniform north, and nonuniform northeast winds. Next, it goes on to simulate the time dependent response of the model to a wind like that observed during an upwelling event along the Cabo Frio Coast (1971), and compares the solution with available observations in space and time.

\section{The observational background of the coastal area of Cabo Frio}

The coastal region of Cabo Frio is located in the Central-Southern Brazilian littoral (Fig. 1) and is characterized by the occurrence of coastal upwelling events. The bottom topography is smooth and flat, with the contours depth tending to follow the coastline. The maximum depth in this coastal area is around 150 meters. The hydrology of the 
water column near Cabo Frio is normally characterized by a thermocline that fluctuates according to the intensity and direction of the winds.

The first evidence for upwelling in this coastal area was reported by Allard (1955), indicating a strong correlation between colder water temperatures and northeast wind, and viceversa. In this region, the coastal upwelling is very sensitive to wind changes (Valentin, et. al., 1987) and two main austral seasons are clearly defined:

a) a spring-summer season, with the tropical maritime anticyclone being established and prevailing E-NE winds favorable to upwelling, and

b) an autumn-winter season, with frequent, passages of cold, polar fronts, and a rapid succession of changing wind cycles unfavorable to upwelling.

An interesting and commonly observed feature of the upwelling in this region is that a tongue of cold water develops off Saquarema. These upwelling events in the coastal region of Cabo Frio were reported by several authors since 1959 , but the contribution of Ikeda et. al., (1974) provides the best description of an upwelling event due to the extensive amount of observations taken. An interesting result was the rapidity of the upwelling process, with the sea surface temperature (SST) attaining its minimum value approximately 24 hours after the first signs of upwelling had appeared. The spatial development and variation of the cold tongue of Sea Surface Temperature was no-less surprising: the upwelling minimum intensified at about 30 nautical miles to the west of Cabo Frio (Fig. 2), and a core of high salinity water moved upwind towards Cabo Frio at an average speed of $1 / 4$ knot, presumably being advected by a surface countercurrent. The possibility for existence of such a current was indicated previously by Mascarenhas et. al. (1971). Southwest winds, caused by atmospheric cold polar fronts, change the circulation pattern of this coastal area by reversing the alongshore currents and generating gyres (Stech \& Lorenzzetti, 1992; Torres \& Santana, 1994).

\section{The model}

The model used in this study, has an active layer overlaying a deep inert layer where the pressure gradient is set to zero. We use a Cartesian coordinate system where $x_{i}$ represents the planar coordinates and the usual summation convention with repeated indices is used. A schematic view of the coastal ocean model is presented in Figure 3 .
For the modeling of the coastal ocean the vertically-integrated non-linear equations of momentum, continuity and transport of SST, are used.

The basic equations are the following :

$$
\frac{\partial U_{i}}{\partial t}+\frac{\partial u_{1} U_{i}}{\partial x_{i}}+\varepsilon_{i i} U_{i}+g h\left\{\sigma \frac{\partial h}{\partial x_{i}}+\frac{h \theta}{2 \mu} \frac{\partial}{\partial} \frac{T}{x_{i}} ;+v U_{i}-\frac{\tau_{i}}{\rho^{u}}=0\right.
$$

$\frac{\partial h}{\partial t}+\frac{\partial U_{i}}{\partial x_{i}}-w_{e}=0$

$$
\frac{\partial T}{\partial t}+u_{i} \frac{\partial T}{\partial x_{i}}+q=0
$$

where

$$
\begin{aligned}
& \varepsilon_{i j}=\left(\begin{array}{cc}
0 & -f \\
f & 0
\end{array}\right), \mu=\rho^{u} / \rho^{\prime}, \sigma=\left(\rho^{\prime}-\rho^{\prime \prime}\right) / \rho^{\prime}, \\
& \bar{\mu}=\mu /(\mu-\sigma)
\end{aligned}
$$

and $u_{i}$, are the velocity components. $U_{i}=u_{i} h$ denotes the corresponding momentum flux in the upper layer and $h$ represents the upper layer thickness. The wind stress components are represented by $\tau_{i}, v$ is the Rayleigh friction coefficient representing the sum of all the dissipative losses, $f$ is the Coriolis parameter and $\rho^{\prime \prime}, \rho^{\prime}$ are ocean water densities in the upper and lower layer respectively. The quantity $\rho^{\prime \prime}$ varies in function of the temperature $T$, according to the expression $\rho^{\prime \prime}=\rho^{\prime}[1$ $\left.\theta\left(T-T^{\prime}\right)\right]$ and $\rho^{\prime}$ is always constant. The sea surface temperature (SST) is represented by $T$, the constant temperature in the lower layer is represented by $T^{\prime}$, and the constant $\theta$ is the coefficient of thermal expansion. The quantity $q$ denotes the source of cooling and warming of SST, and it is approximated by

$$
\begin{array}{ll}
q=\omega T^{*} / h & , \text { for } T>T^{\prime} \\
q=0 & , \text { for } T \leq T^{\prime}
\end{array}
$$

in which $\omega$ is a vertical velocity defined equal to $\partial U / \partial x_{i}$, and $T^{*}$ is the temperature at the interface (the mean value of $T$ and $T$ ), that means, $q$ depends directly to the divergence or convergence of the flows. 

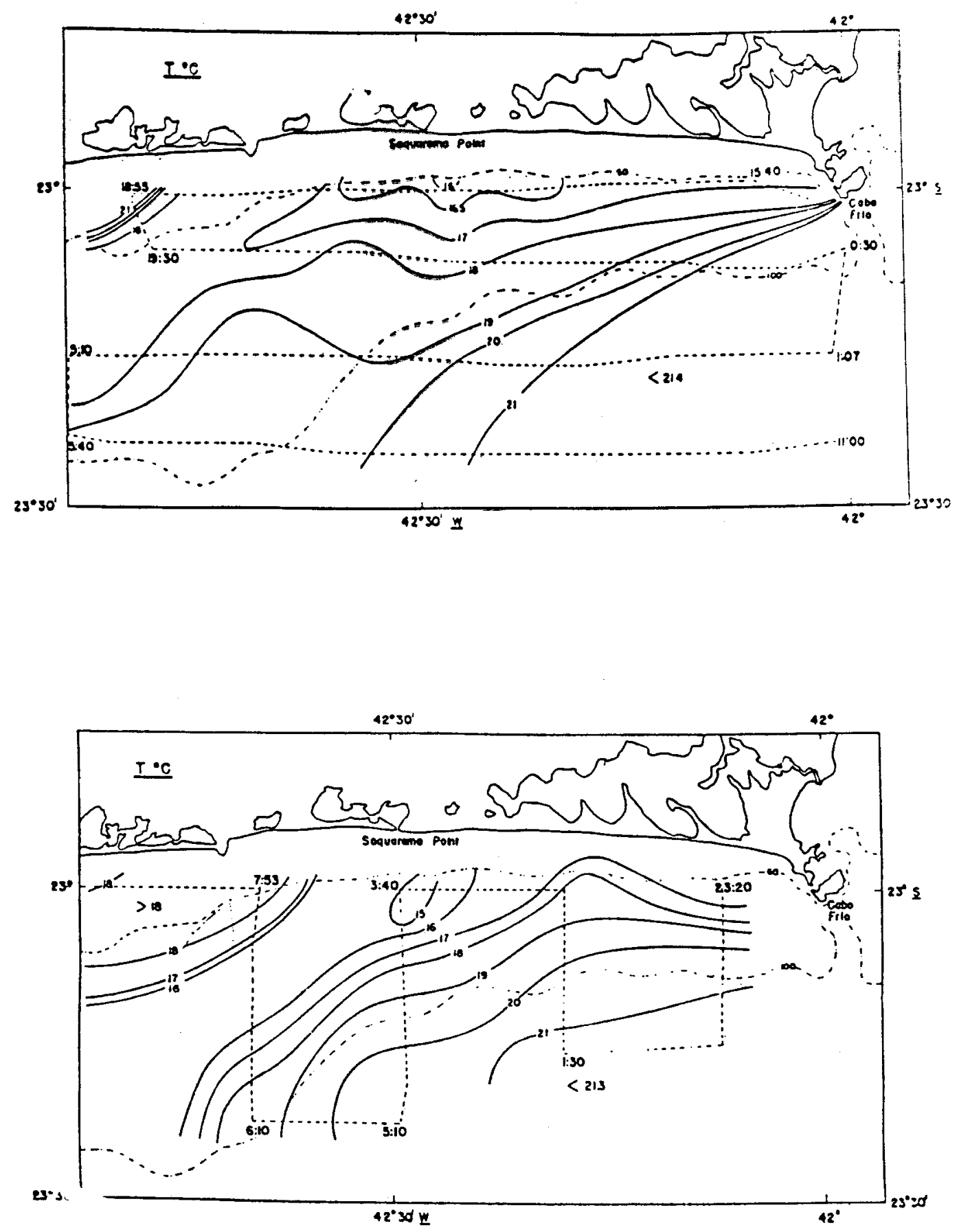

Fig. 2. Charts of sinoptic observations (Ikeda et al., 1974). In the upper panel. SST field with information collected from 14:00 hours of $08 / 20 / 71$ to $11: 00$ hours of $08 / 21 / 71$. In the lower panel. SST field with information collected lrom 23:00 hours of $08 / 24 / 71$ to $10: 30$ hours of $08 / 25 / 71$. 


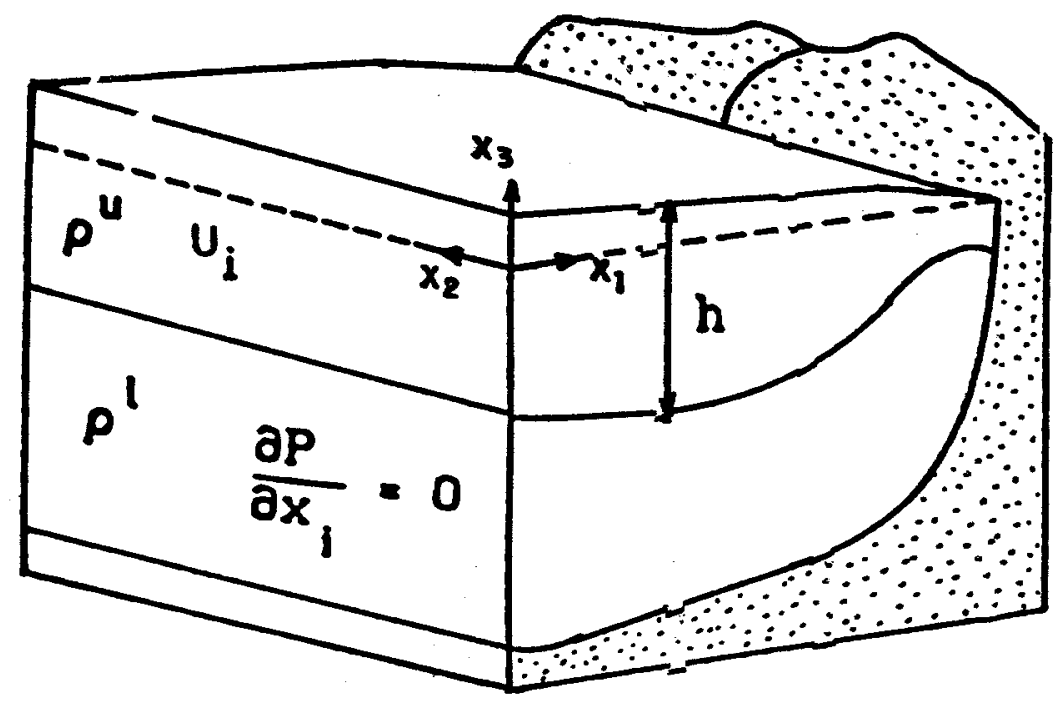

Fig. 3. The $1 \frac{1}{2}$ layer model layout.

Here, the entrainment velocity $w_{\mathrm{e}}$ only prevents the interface between the two layers from surfacing (McCreary \& Kundu, 1988) and is defined by the smoothing function

$$
\begin{array}{ll}
w_{e}=\left(H_{e}-h\right)^{2} / t_{e} H_{e} & \text {, for } h<H_{e} \\
w_{e}=0 & \text {,for } h \geq H_{e}
\end{array}
$$

where $H_{c}$ is the entrainment thickness and $t_{c}$ the entrainment time-scale.

For the coastline, non-slip boundary conditions are prescribed and homogeneous conditions for $h, T$ are assumed. The weakly reflective condition applied at the open boundaries, based on the characteristic method, is written in an axis normal to the boundary $\left(x_{n}\right)$, in the following form:

$$
\frac{\partial\left(U_{n} \pm c h\right)}{\partial t}+c \frac{\partial\left(U_{n} \pm c h\right)}{\partial x_{n}}+G=0
$$

where,

$$
c=\sqrt{g \sigma h}, \text { and } G=F \pm c h
$$

$$
F=\frac{g h^{2} \theta}{2 \mu} \frac{\partial T}{\partial x_{n}}-\frac{\tau_{n}}{\rho^{u}}+v U_{n}+\frac{\partial\left(u_{n} U_{n}\right)}{\partial x_{n}}+\varepsilon^{*}
$$

$b=-w_{e}$

and $\varepsilon^{*}$ is the Coriolis term in the normal direction. $u_{n}$ , $U_{n}$ denote the velocity and flux along the axis $x_{n}$. The weakly reflective conditions in the upper layer are defined by the in-going characteristic of the presented equations.

\section{Finite difference solution scheme}

The basic equations for the 1 1/2 layer model, can be written in a general matrix form as :

$$
\frac{\partial Z}{\partial t}+\underline{A} \frac{\partial Z}{\partial x_{1}}+\underline{B} \frac{\partial Z}{\partial x_{2}}+(\underline{C}+\underline{D}) Z+E=0
$$

where $Z$ represents the vector variable, $E$ the vector of sources and sink and $\underline{A}, \underline{B}, \underline{C}$ and $\underline{D}$ are the matrix, described by. 
$Z=\left(\begin{array}{c}l \\ I^{\prime} \\ 2 \\ h \\ T\end{array}\right)$

$\underline{\mathrm{A}}=\left(\begin{array}{cccc}2 u_{1} & 0 & g h \sigma-u_{1}^{2} & g h^{2} \theta / 2 \vec{\mu} \\ u_{2} & u_{1} & -u_{1} u_{2} & 0 \\ 1 & 0 & 0 & 0 \\ 0 & 0 & 0 & u_{1}\end{array}\right)$,

$\underline{C}=\left(\begin{array}{cccc}0 & -f & 0 & 0 \\ f & 0 & 0 & 0 \\ 0 & 0 & 0 & 0 \\ 0 & 0 & 0 & 0\end{array}\right)$

$\underline{\mathrm{B}}=\left(\begin{array}{cccc}u_{2} & u_{1} & -u_{1} u_{2} & 0 \\ 0 & 2 u_{2} & g h \sigma-u_{2}^{2} & g h^{2} \theta / 2 \bar{\mu} \\ 0 & 1 & 0 & 0 \\ 0 & 0 & 0 & u_{2}\end{array}\right)$,

$\underline{\mathrm{D}}=\left(\begin{array}{llll}v & 0 & 0 & 0 \\ 0 & v & 0 & 0 \\ 0 & 0 & 0 & 0 \\ 0 & 0 & 0 & 0\end{array}\right)$

$E=\left(\begin{array}{c}-\tau_{1} / \rho^{\prime \prime} \\ -\tau_{2} / \rho^{u} \\ -w_{e} \\ q\end{array}\right)$

To establish the numerical model, we introduce a set of points $\left(x_{1}, x_{2}, t\right)=\left(k \Delta x_{1}, l \Delta x_{2}\right.$, $m \Delta t)$ of a discrete grid. The discrete vector variable $Z\left(x_{1}, x_{2}, t\right)$ was placed in the same nodes of the grid such that the vector variable is described in the grid as $Z_{k, l}^{m}=Z\left(k \Delta x_{1}, l \Delta x_{2}, m \Delta t\right)$.

The finite difference approximation is based in centered differences in space and a forward difference in time using a dissipative interface. Considering $\Delta x_{1}=\Delta x_{2}$ and defining the centered difference operator $\delta$ and the forward difference operator $\lambda$ as:
$\delta_{k}\left(Z_{k, l}^{m}\right)=\frac{Z_{k+1, l}^{m}-Z_{k-1, l}^{m}}{2 \Delta x}, \quad \lambda^{m}\left(Z_{k, l}^{m}\right)=\frac{Z_{k, l}^{m+1}-Z_{k, l}^{*}}{\Delta}$

where

$$
Z_{k, l}^{*}=\alpha Z_{k+1, l}^{n}+\alpha Z_{k-1, l}^{n}+(1-4 \alpha) Z_{k, l}^{m}+\alpha Z_{k, l+1}^{n}+\alpha Z_{k, l-1}^{n}
$$

is the dissipative interface ; then the finite difference formulation takes the Lax-Wendroff scheme form

$$
\lambda^{m}\left(Z_{k, l}^{m}\right)+\underline{A} \delta_{k}\left(Z_{k, l}^{m}\right)+\underline{B} \delta_{l}\left(Z_{k, l}^{m}\right)+\underline{C} \bar{Z}_{k, l}^{m}+\underline{D} Z_{k, l}^{m+1}+E_{k, l}^{m}=0
$$

where $\bar{Z}$ represent the mean value vector. The parameter $\alpha$ ranges in the interval $0<\alpha \leq 1 / 4$. If $\alpha$ $=1 / 4$ the resulting scheme is the called Lax scheme. Here, it is used the value of $\alpha=1 / 8$. In each open boundary point there are flux and level unknowns. First, the flux at the boundaries is evaluated using the finite-difference approximation described by (12), but replacing the centered finite-difference $\delta$, operator by lateral finite-difference operator $\vartheta_{B}$

$\vartheta_{B}\left(R_{B}^{m}\right) \equiv \frac{1}{2 \Delta x}\left[3 R_{B}^{m}-4 R_{B-1}^{m}+R_{B-2}^{m}\right]$

where $R$ represents the variable and the subscript " $B$ " indicates the boundary point, and the decreasing points " $B-1, B-2 "$ are interior points in an axis normal to the boundary. After that, we obtain $h$ at $m+1$ time level, solving equation ( 8 ) by the following approximation

$\frac{\left[U_{B}^{m+1} \pm c h_{B}^{m+1}\right]-\left[U_{B}^{*} \pm c h_{B}^{*}\right]}{\Delta}+c \vartheta_{B}\left(U_{B}^{m} \pm c h_{i}^{m}\right)+G_{B}^{m}=0$

where $U^{*}$ and $h^{*}$ are the dissipative interface for $U$ and $h$ at the boundary points.

\section{Results}

Here, solutions are evaluated for a coastal ocean forced by uniform and non-uniform wind fields. The experiments are focused to the rapid change of dynamic conditions. A coordinate system with $x_{1}$ positive eastward and $x_{2}$ positive northward is used. The $1 \frac{1}{2}$ layer model of the coastal region of Cabo Frio is forced by wind fields which have a 
spatial structure. Unless specified otherwise, the parameter used in the experiments, are the following: The fluid in the layers are initially at rest and the initial value of $h=30 \mathrm{~m}$. The densities are assumed $\rho^{u}=1024 \mathrm{~kg} / \mathrm{m}^{3}, \rho^{l}=1025 \mathrm{~kg} / \mathrm{m}^{3}$. The Coriolis parameter correspond to the $23^{\circ} \mathrm{S}$ and taken as $f=-5.68 \times 10^{-5} \mathrm{sec}^{-1}$. The Rayleigh friction coefficient is fixed at $v=2 \times 10^{-5}$ $\mathrm{sec}^{-1}$. The initial temperatures in the layers are assumed as $T=23^{\circ} \mathrm{C}$ and $T^{\prime}=15^{\circ} \mathrm{C}$ and the coefficient of thermal expansion is $\theta=2.6 \times 10^{-4}$ $\left({ }^{\circ} \mathrm{C}\right)^{-1}$. The time step is $\Delta \mathrm{t}=600 \mathrm{sec}$, the entrainment thickness is fixed in $H_{e}=30 \mathrm{~m}$ and $t_{c}=1 / 4$ day. The coastal ocean is limited to a rectangle of $1^{\circ} 30^{\circ}$ by $1^{\circ}$ using an uniform grid spacing of $\Delta x=1 / 60^{\circ}$; the number of dynamic grid points are 3902. The computational boundaries are partly open and partly closed.

It was necessary several experiments to chose the mentioned parameters which are the mores adequate to simulate the mean features of the hydrodynamic and thermodynamic transient response of the coastal waters of Cabo Frio (calibrated which the numerical simulation described in section Numerical simulation of a time-dependent upwelling event).

\section{Response to uniform east winds}

Figure 4 shows the model response at day 2 and 5 when it is forced by uniform east winds $\left(\tau_{1}=0.16 \mathrm{~N} / \mathrm{m}^{2}\right.$ ).

At day 2, along the zonal coastline, an upwelling band is generated by the geostrophic motion of waters in the upper layer shoaling the $h$ field, increasing the entrainment influence and decreasing $T$. The cooling of the SST is significant, decreasing by almost $7^{\circ} \mathrm{C}$ in the alongshore band. Due the coastline configuration the band is initially extended up to the Cabo Frio cape. In the meridional coastline of the coastal region there are not signals of upwelling.

At day 5 the colder water band, generated along the zonal coastline, is wider and turns around the Cabo Frio. This is due dynamical consequences of the coastal configuration (cape) which generates Kelvin waves in a manner similar to the wind variability as reported by Crepon et al. (1984).

During the experiment, the current system shows a wind dependent response. Along the zonal coastline it is possible to note that close to the shore, the alongshore velocity component is stronger in comparison to the offshore side, indicating the presence of a coastal jet.
In Figure 5, is presented the time dependent variation of the velocity components and SST off Saquarema and Buzios. In the zonal coastline (off Saquarema) the cooling of the waters reaches the minimum of $15^{\circ} \mathrm{C}$ in an period as short as 2 days and the velocity components show a flow in eastward direction $\left(u_{1}<0\right)$ with a small component in southward direction $\left(u_{2}<0\right)$ and when the waters reach the minimum SST of $15^{\circ} \mathrm{C}$, the velocity component in offshore direction increases and the alongshore component decreases (because the term $\partial T / \partial x_{i}$ is suppressed and influence of the term - $f u_{2}$ increases).

In the meridional coastline (off Buzios), the onshore flow $\left(u_{1}\right.$ component) forced by the wind during the first stages is suppressed shortly thereafter (14 hours) the first signals of cooling of the SST, due the Kelvin wave motion (see SST off Buzios).

\section{Response to uniform north winds}

Figure 6 shows the model response at day 2 and 5 when it is forced by north winds $\left(\tau_{2}=0.16 \mathrm{~N} / \mathrm{m}^{2}\right)$. In the zonal coastline, close to the shore, the upwelling is weak in comparison to the upwelling generated in the east wind case. The presence of cold upwelled water is due the ageostrophic motions only, forced by the nort? wind. In the offshore side due the genstromic infiuence a zonal current is generated tiviving in eastward direction. This can explain the countercurrent reported in many occasions in this coastal area.

In the meridional coastline of this region, upwelling centers are generated with a stronger intensity in the downwind side of the capes as observed at day 2. At day 5 the favorable winds help to increase the cold upwelling band. The area of stronger upwelling is extended up to Cabo Frio.

In Figure 7 is presented the history of SST and the velocity components in the control points. The SST reaches a minimum only at day 5 olf Buzios. Note that the $u_{1}$ component off Buzius increases a little more during the day 5 , after the SST reaches the minimum at day 4 . In the control point off Saquarema, the flow is going offshore with a deflection in eastward direction $\left(u_{1}>0\right)$.

\section{Response to a non-uniform wind field}

This experiment evaluates the solution using a possible idealized representation of the mean features of the observed wind field during an upwelling event in august of 1971. 

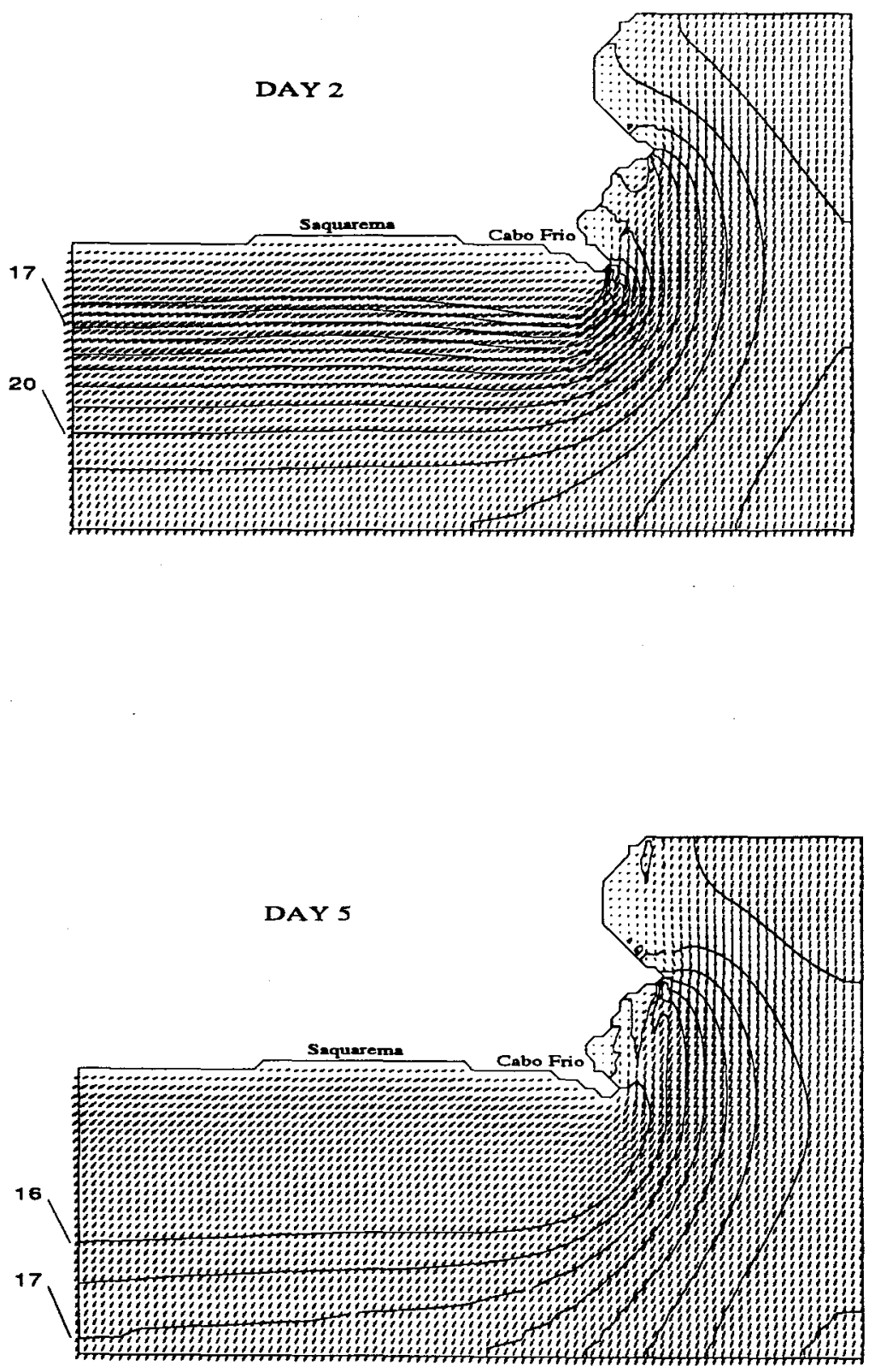

Fig. 4. East wind solution. SST and currents at day 2 and 5. The SST contour interval is $0.5^{\circ} \mathrm{C}$ and the velocity arrows are normalized to the maximum of $23.6 \mathrm{~cm} / \mathrm{sec}$ at day 2 and 18.3 $\mathrm{cm} / \mathrm{sec}$ at day 5 . 

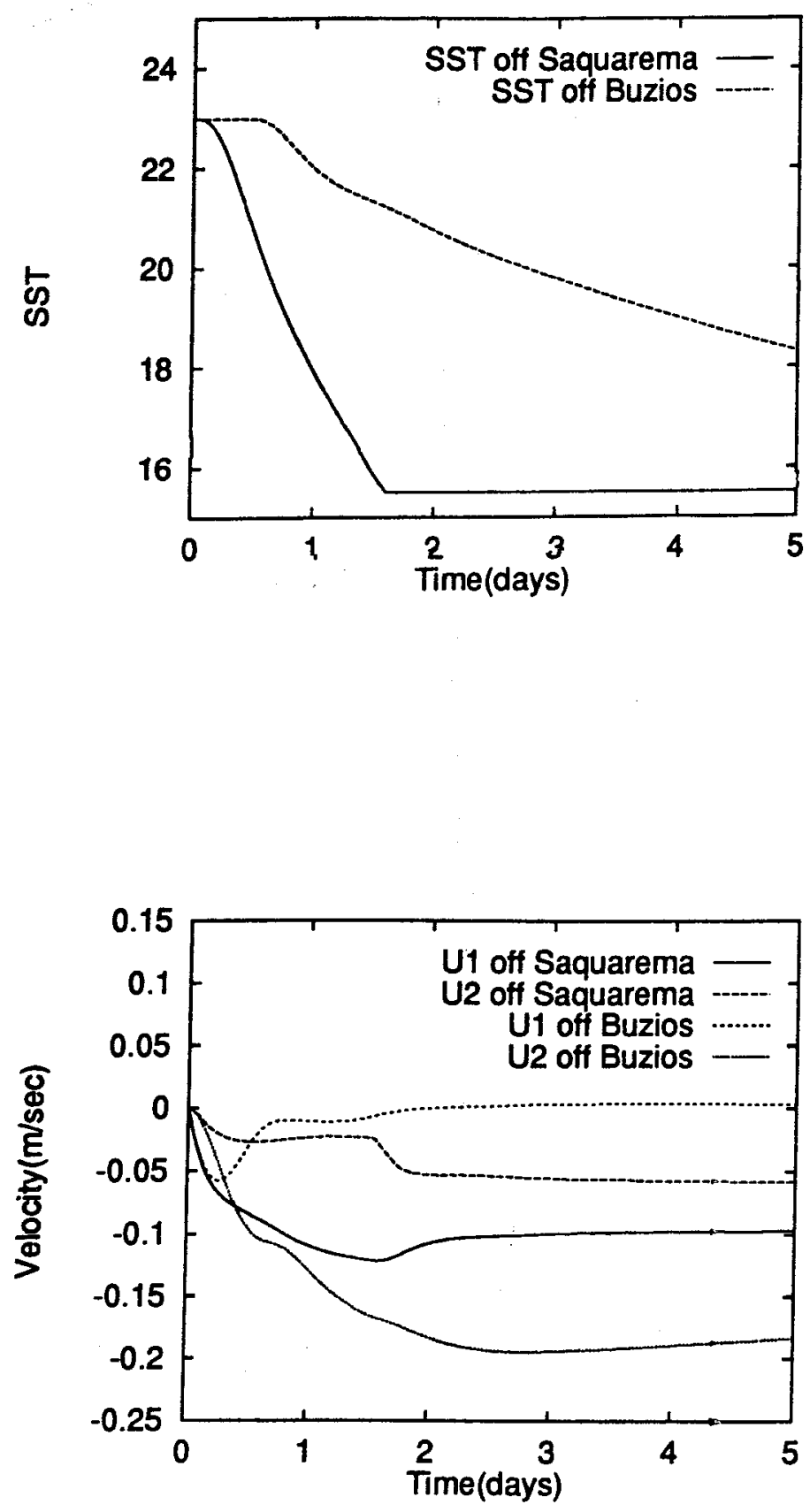

Fig. 5. Time history of SST and velocity components off Saquarema and Buzios ( $5 \mathrm{~km}$ in front) for the east wind solution. 

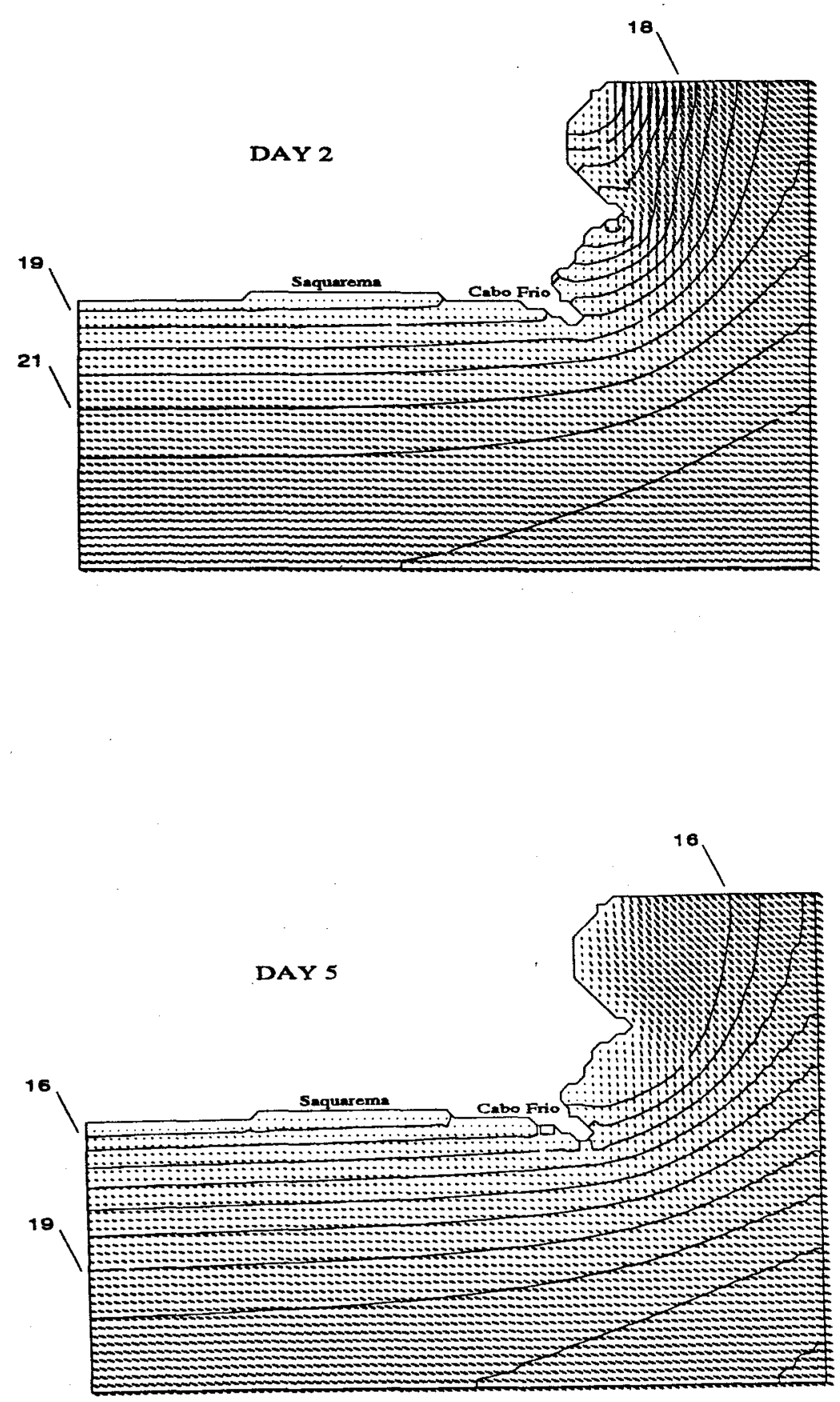

Fig. 6. North wind solution. SST and currents at day 2 and 5. The SST contour interval is $0.5^{\circ} \mathrm{C}$ and the velocity arrows are normalized to the maximum of $12.6 \mathrm{~cm} / \mathrm{sec}$ at day 2 and 10.7 $\mathrm{cm} / \mathrm{sec}$ at day 5 . 

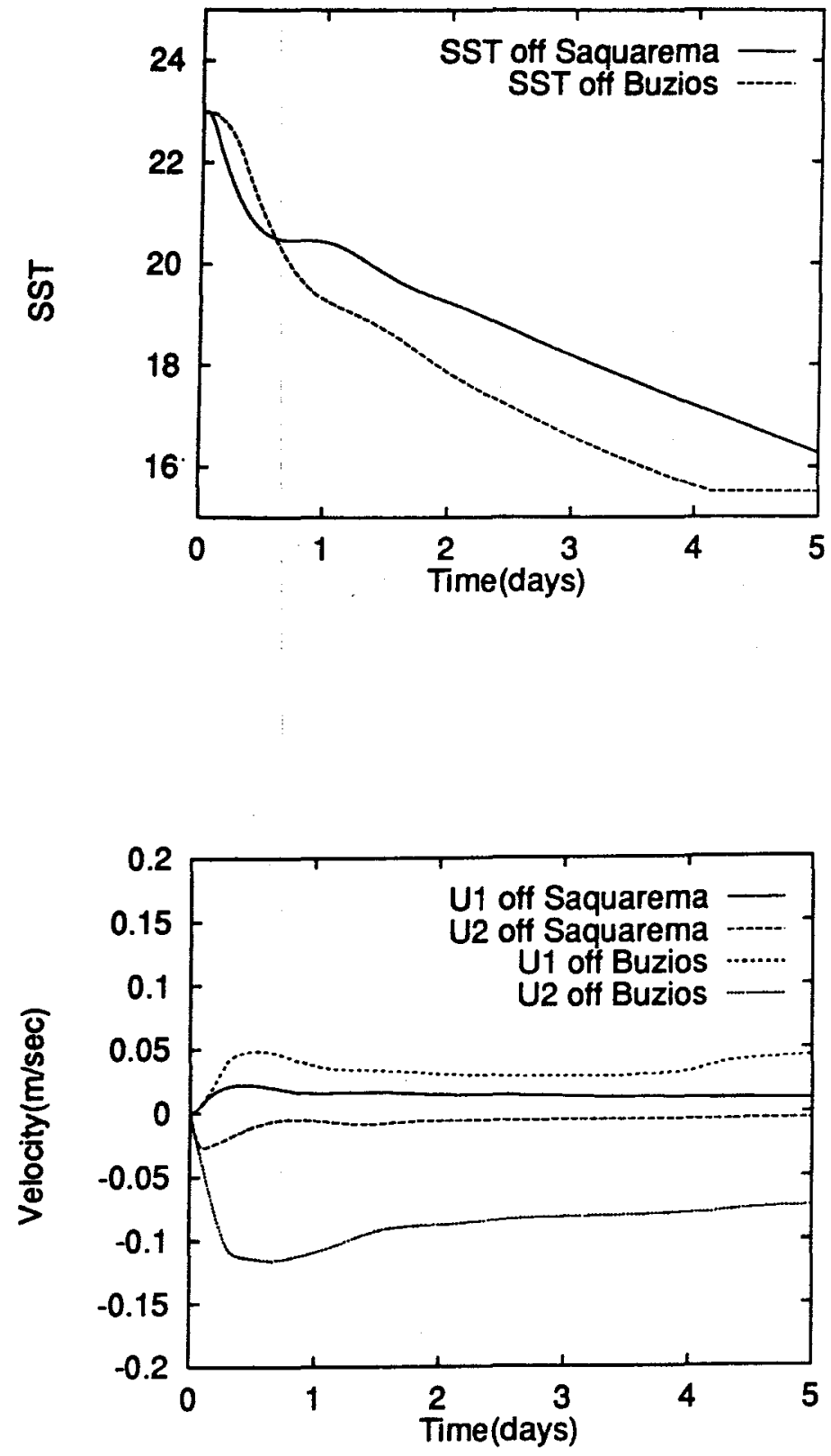

Fig. 7. Time history of SST and velocity components off Saquarema and Buzios (5 km in front) for the north wind solution.

Non uniform wind fields are described by the composition of patches of the form

$$
\tau_{1}=\tau_{01} \psi_{1}\left(x_{1}, x_{2}\right), \tau_{2}=\tau_{02} \psi_{2}\left(x_{1}, x_{2}\right)
$$

where $\psi_{1}\left(x_{1}, x_{2}\right), \psi_{2}\left(x_{1}, x_{2}\right)$ are the twodimensional structures of the patches and $\tau_{01}(l)$, $\tau_{02}(l)$ are time dependent functions. The Figure 8 shows the two-dimensional structures $\psi_{1}\left(x_{1}, x_{2}\right), \psi_{2}\left(x_{1}, x_{2}\right)$ used in the model and the resulting wind field. In this case, $\tau_{01}(t)$ and $\tau_{02}(t)$ are constant in time and prescribed as $\tau_{01}=-0.11 \mathrm{~N} / \mathrm{m}^{2}, \tau_{02}=-0.11 \mathrm{~N} / \mathrm{m}^{2}$. 
The Figure 9 illustrates the response of the non-linear model to the non-uniform wind forcing, showing the velocity and the SST fields at day 2 . After 2 days a tongue of upwelled cool water is generated and extended in south-westward direction reaching a minimum in front of Saquarema. In this sector the SST reaches the minimum of $15^{\circ} \mathrm{C}$. Warmest temperatures occur well offshore and eastward approaching its initial value. The velocity field shows a current going offshore, which is forming at the coast and by continuity has flow contribution along the coast from the east side as a coastal current and from the west side as a coastal countercurrent. The maximum velocity obtained in the flow field is $17.7 \mathrm{~cm} / \mathrm{sec}$. The calculated SST pattern is similar to the observed one (upper panel of Fig. 2) characterized by the upwelling center in front of Saquarema and a spreading of cool waters of around $17.5^{\circ} \mathrm{C}$ in southwestward direction.

\section{Numerical simulation of a time-dependent upwelling event}

In this numerical simulation, the model of the coastal region of Cabo Frio is forced by a wind lield which has a spatial structure and a time variability. The wind fields are composed of patches of the form described in (15). The horizontal structure of the wind stress components are proposed taking into account observed pattern. The structures $\psi_{1}\left(x_{1}, x_{2}\right), \psi_{2}\left(x_{1}, x_{2}\right)$ used in the model are the same showed in Figure 8. The hourly observations (Fig. 10) at an industrial meteorological station ("Companhia Nacional de Alcalis", situated on the coast a little west of Cabo Frio) were corrected in order to extrapolate for the ocean, increasing the wind velocities in a $30 \%$. The time variation of the wind stress functions $\tau_{01}(t)$ and $\tau_{02}(t)$ were calculated using the aerodynamic square law. In this simulation, for calibration purposes, were chosen values for the wind drag coefficient $c_{w}=2.25 \times 10^{-3}$ and the Rayleigh friction coefficient $v=1.8 \times 10^{-5}$ $\sec ^{-1}$.

The observed wind velocities at the beginning of the upwelling event were very weak $(2 \mathrm{~m} / \mathrm{sec})$ and upwelling conditions were not reported. Additionally, information about the wind pattern and direction before the initial date was not enough to define a correct initial state, therefore, the initial conditions were defined at rest, which are acceptable to represent ocean condition under veak winds. The simulation of the upwelling is started at 0 hours of $08 / 18 / 71$ and integrated forward in time during 3 days to compare with observed spatial SST patterns, presented in Figure 2, and the time evolution of the SST in the coastal station of Cabo Frio.

Figure 11 illustrates the response of the nonlinear model to the time dependent and non-uniform wind forcing, showing the velocity and the SST fields at 2 and 3 days. After 2 days a tongue of upwelled cool water is generated and extends in south-westward direction reaching a minimum temperature of $16.3^{\circ} \mathrm{C}$ in front of Saquarema. Note that a cool water cell enclosed by a contour of $17^{\circ} \mathrm{C}$ is formed offshore. This cell is mainly a consequence of the changes in direction and magnitude of the wind forcing. Remember that in the previous test calculation, using the same spatial structure of the wind but constant in time, the cool water cell offshore is not present in the solution after 2 days (Fig. 9).

After 3 days the tongue of cool water is more intense, due the persistence of favorable wind. It reaches an absolute minimum of $15^{\circ} \mathrm{C}$ in a band between Saquarema and Cabo Frio which extends offshore in south-west direction. Warmest temperatures occur well offshore and eastward approaching its initial value, and SST rises to $23^{\circ} \mathrm{C}$. The velocity field shows a current flowing offshore, which is being formed at the coast and by continuity has flow contribution along the coast, from the east side as a coastal current and from the west side as a coastal counterflow. In the offshore side, there is a drift in eastward direction which is not really a surface countercurrent, it is only a deflection of the flow due the response of the coastal water to the non-uniform wind field forcing used in this simulation, with a tendency to form a cyclonic gyre. The maximum velocity at third day is 26.5 $\mathrm{cm} / \mathrm{sec}$.

Figure 12 shows the calculated time dependent variations of the SST in points representing Saquarema (at the shore) and the coastal station of Cabo Frio. The time-dependent patterns in these points are particularly similar to the observed in the coastal station of Cabo Frio. The SST dropping is very intensive during the second day due higher wind velocities. A wind relaxation during the third day increases the SST during some hours.

The results indicate that the model describes remarkably well the time-dependent physical features of the observed coastal upwelling and the rapid change of SST in the coastal region of Cabo Frio. The modeling results give support to the hypothesis that the spatial pattern of the tongue of upwelling in this region is mainly driven by the spatial configuration of wind field in this coastal region. 


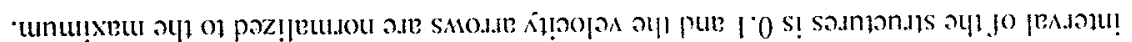

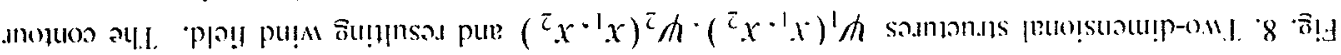
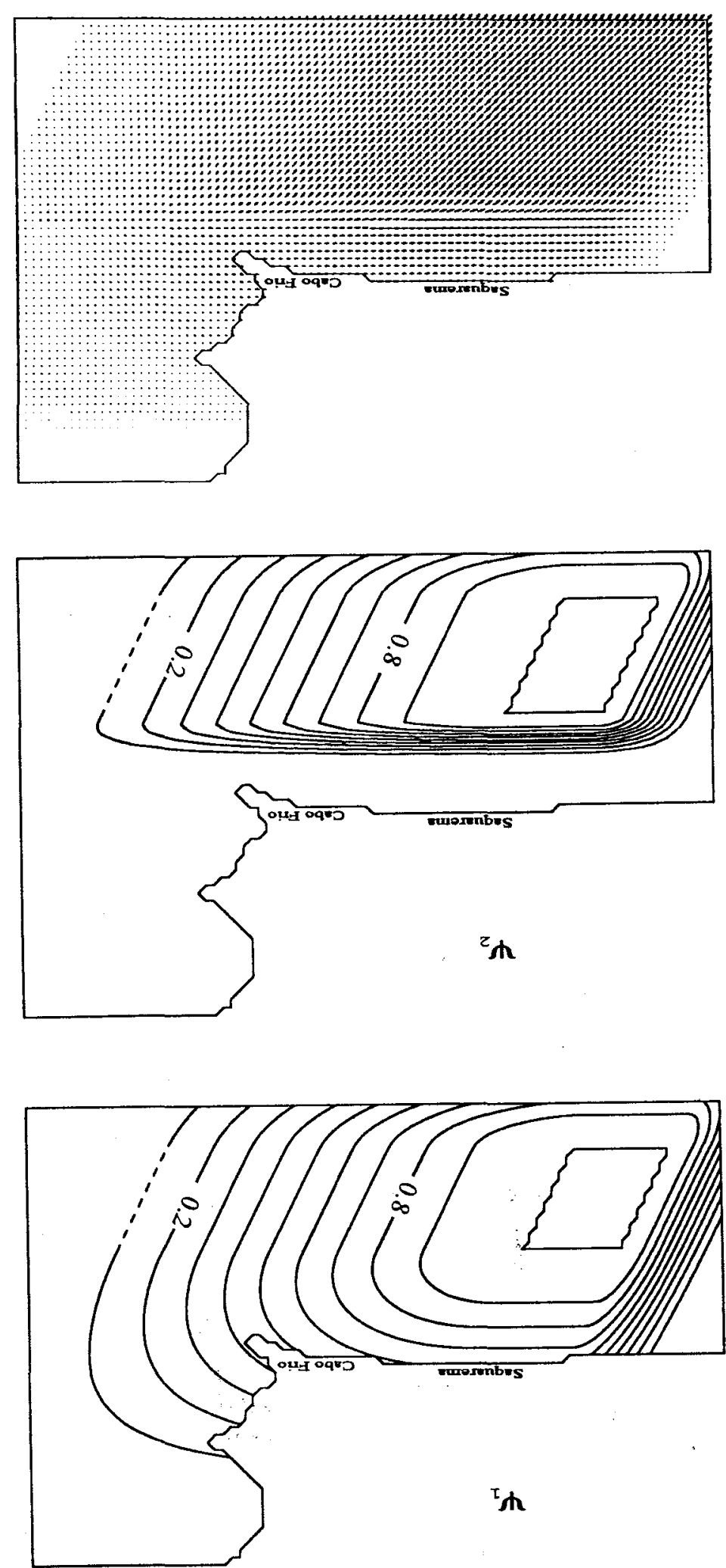


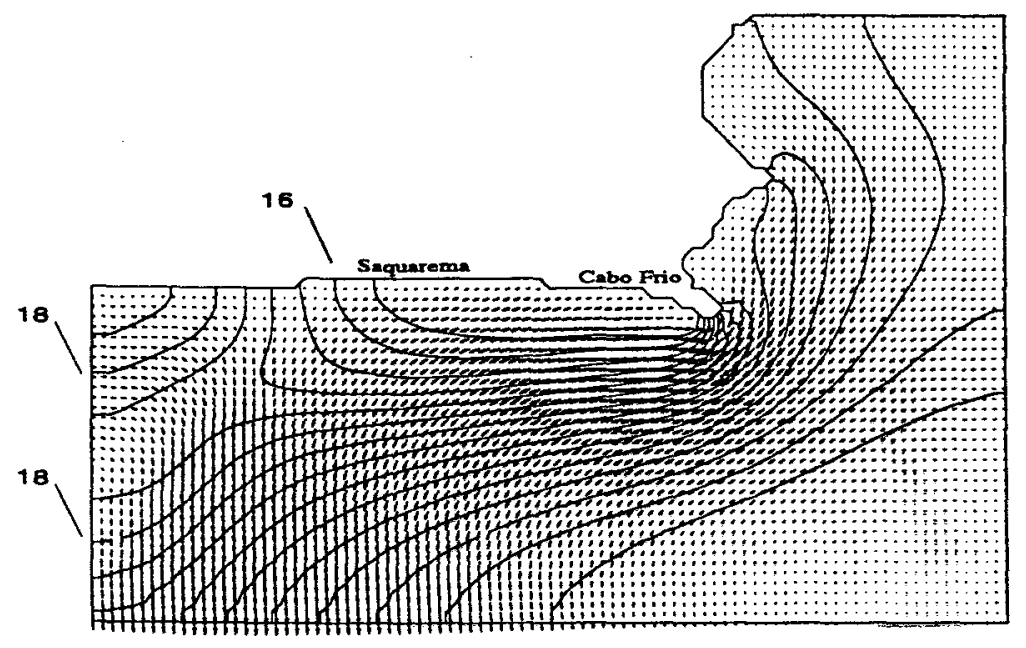

Fig. 9. Solution by non-uniform wind field. The arrows are normalized to the maximum velocity of 17.7 $\mathrm{cm} / \mathrm{sec}$ and the contour interval of the SST is $0.5^{\circ} \mathrm{C}$.

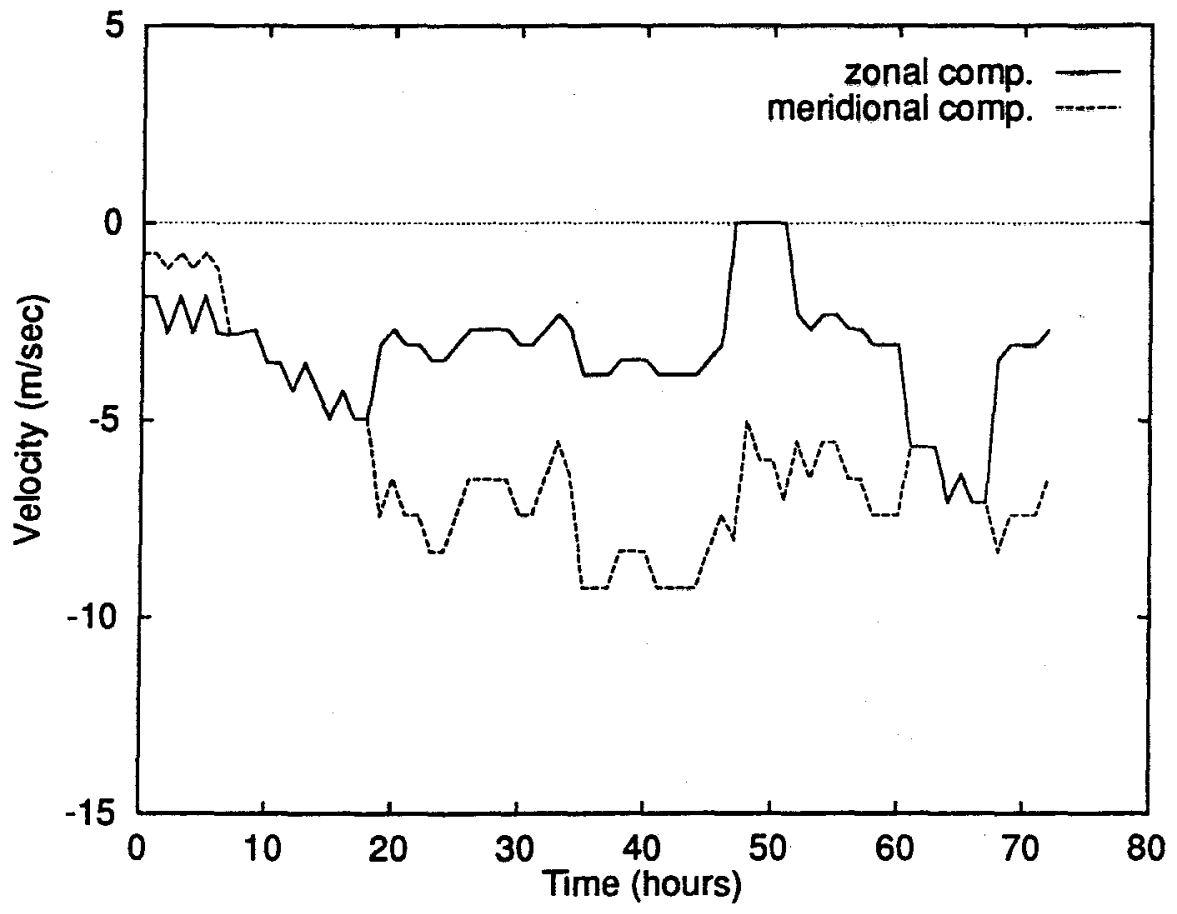

Fig. 10. Local time variations of the wind velocity (in components) collected in a meteorological station a little west of Cabo Frio. 

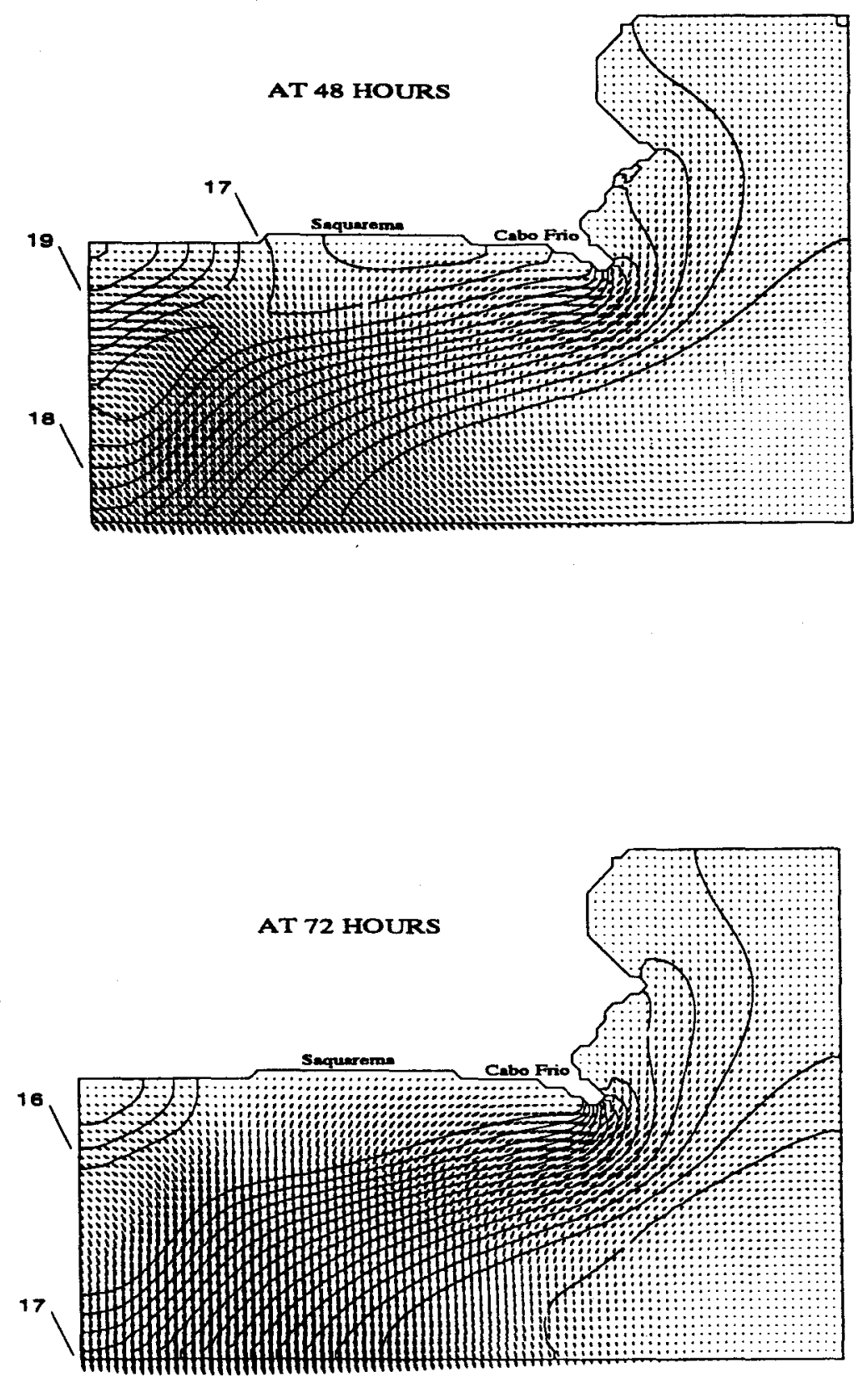

Fig. 11. Simulation results of the Cabo Frio model. The arrows are normalized to the maximum velocity and the contour interval of the SST is $0.5^{\circ} \mathrm{C}$. At 48 hours after the wind is blowing the upwelling center is located in front of Saquarema delimited by the SST contour of $16.5^{\circ} \mathrm{C}$, the maximum velocity is 19.9 $\mathrm{cm} / \mathrm{sec}$. $\Lambda \mathrm{t} 72$ hours, the minimum SST contour of $15.5^{\circ} \mathrm{C}$ delimited a band of cold water extended offitore in south-west direction and the maximum velocity is $26.5 \mathrm{~cm} / \mathrm{sec}$. 


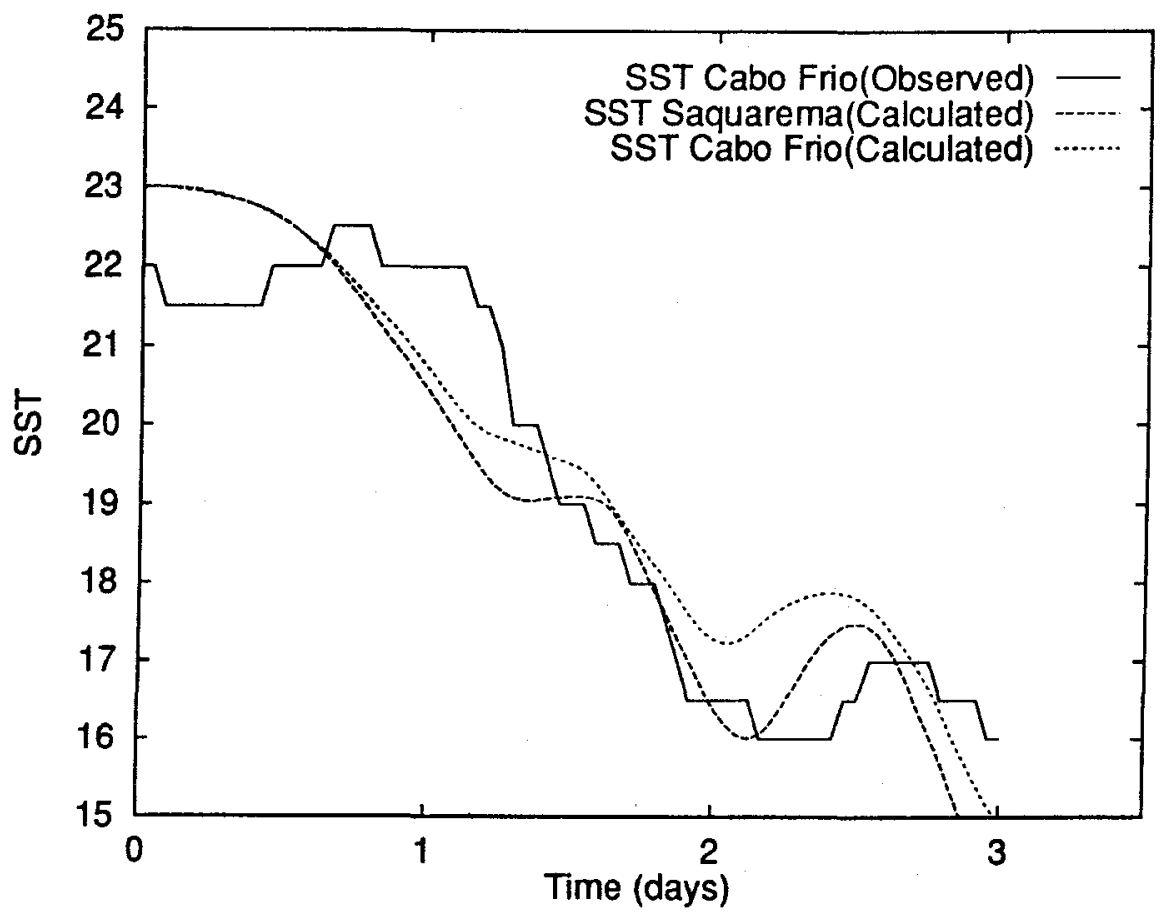

Fig. 12. Time history of the computed SST in the coastal points of Saquarema and Cabo Frio and the observed SST in the coastal station of Cabo Frio.

\section{Conclusions}

A model for the coastal area of Cabo Frio (Rio de Janeiro - Brazil), based on the non-linear $11 / 2$ layer model, is presented. The model includes the hydrodynamic momentum and continuity equations; a thermodynamic equation to describe the changes of SST, and a properly treatment of the open boundaries. The equation system is approximated by the finite difference method.

It was analyzed the dynamic response of the coastal region of Cabo Frio. East winds generates an upwelling band along the zonal coastline of the region. North winds produces a weak ageostrophic upwelling at the zonal coastline but offshore a eastward flow is obtained. In this case, along the meridional coastline of the region, the upwelling is more intense. When the model is forced by a nonuniform wind field, representing an idealized wind pattern of the region, it was possible to reproduci a plume of cool upwelled water which intensifics in southwest direction. In this experiment it was verified the presence of coastal eastward llows. The presence of eastward flows in the solutions, associated with north wind components, might explain the presence of "countercurrents" reported in many occasion in this coastal area.

A time-dependent simulation of an upwelling event in 1971 is obtained successfully. The model is firced by a time dependent wind field with an idealized spatial structure. The results describe the rapid evolution, during 3 days, of a plume of cool upwelled water extended in southwest direction, and the time response of the SST in the Cabo Frio station. These results compare remarkably well with the observations in space and time. The calculated current system is characterized by a current flowing offshore, which is formed at the coast, and by signals of eastward flows offshore. During the simulation, due the changes of magnitude and wind direction, cells of cool upwelled water separate from the initial upwelling center flowing in southwest direction. The modelling result gives support to the hypothesis that the observed tongue of upwelling is mainly driven by the spatial configuration of wind field in this coastal region.

Conclusively, the successfully obtained results in the numerical experiments validate the conceptual formulation of the model presented in this paper. Improvements of the model for further application is possible increasing the complexity with processes which were not consider in this paper.

\section{Acknowledgements}

The author was supported by $\mathrm{CNPq}$ grant no. $381575 / 97-7$. Thanks to the reviewers, their comments were helpful in improving the manuscript. 


\section{References}

Allard, P. 1955. Anomalies dans les températures de l'eaux de mer observées au Cabo Frio (Brésil). Bull. Inf. Com. cent. Oceanogr. Études Côtes, 2: 58-63.

Carbonel, C. 1982. Numerisches model der zirkulation in auftriebsgebieten mit anwendung auf die Nord-Peruanische Kueste. Ph.D. Thesis. Institute fuer Stroemungsmechanik, Hannover Universitaet. 92p.

Carbonel, C. 1992. Numerical modeling of layered ocean fluids on a limited-area domain. Relatorio 33. Instituto Politécnico do Rio de Janeiro. 35p.

Crepon, M. \& Richez, C. 1982. Transient upwelling generated by two-dimensional atmospheric forcing and variability in the coastline. J. phys. Oceanogr., 12(12):1437-1457.

Crepon, M.; Richez, C. \& Chartier, M. 1984. Effects of coastline geometry on upwelling. J. phys. Oceanogr., 14(8):1365-1382.

Chapman, D.C. 1985. Numerical treatment of cross-shelf open boundaries in a barotropic coastal ocean model. J. phys. Oceanogr., 15(8): 1060-1075.

Guillen, O. \& Calienes, R. 1981. Upwelling off Chimbote. In: Richards, F. A. ed. Coastal upwelling. American Geophysical Union. p.312326.

Hurlburt, H. E. 1974. The influence of coastline geometry and bottom topography on the eastern ocean circulation. Department of Meteorology Florida State University, Tallahase.

Ikeda, Y.; Miranda, L. B. \& Rock, N. J. 1974. Observations on stages of upwelling in the region of Cabo Frio (Brazil) as conducted by continuous surface temperature and salinity measurements. Bolm Inst. oceanogr., S Pauto, 23:33-46.
Mascarenhas Jr., A. S.; Miranda, L. B. \& Rock, N. J. 1971. A study of oceanographic conditions in the region of Cabo Frio. In: Costlow Jr.. J. D. ed. Ferilitty of the sea. New York, Gordon \& Breach Science Publishers. p. 285-308.

McCreary, J. P. \& Kundu, P. 1988. A numerical investigation of the Somali Current during the Southwest Monsoon. J. mar., Res., 46(1):25-58.

McCreary, J. P.; Lee, H. S. \& Enfield, D. B. 1989. The response of the coastal ocean to strong offshore winds: with application to circulations in the Gulfs of Tehuantepec and Papagayo. J. mar. Res., 47(1):81-109.

Stech, L. \& Lorenzzetti, J. 1992. The response of the South Brazil Bight to the passage of wintertime cold fronts. J. geophys. Res., 97(C6):95079520 .

Torres A. \& Santana, A. I. 1994. Resposta local da ressurgência costeira de Cabo Frio a passagem de um sistema frontal. Pesquisa Naval, 7:107116.

Valentin, J.; Andre, D. L. \& Jacobs, S. A. 1987. Hydrobiology in the Cabo Frio (Brazil) upwelling: two-dimensional structure and variability during a wind cycle. Continent. Shelf Res., 7(1):77-88.

Verboom, G. K. 1982. Weakly-reflective boundary conditions for the shallow water wave equations. Delft Hydraulic Laboratory. Publication n. 266. $14 p$.

Verboom, G. K.; Stelling, G. S. \& Officier, M. J. 1983. Boundary conditions for the shallow water equations. In: Abbott, M. B. \& Cunge, J. A. eds Engineering applications of computational hydraulics I. Boston, Pitman. p.230-262.

(Manuscript received 18 July 1997; revised 24 March 1998; accepted 15 April 1988) 